С. М. Кузнеиов, Ю. С. Косолапов, А. Д. Дармаев и др. Онкологические казусы при диагностике соединительно-тканных злокачественных опухолей у лиц молодого возраста

УДК 616-006.04

DOI: $10.18101 / 2306-1995-2020-1-9-20$

\title{
ОНКОЛОГИЧЕСКИЕ КАЗУСЫ ПРИ ДИАГНОСТИКЕ СОЕДИНИТЕЛЬНО-ТКАННЫХ ЗЛОКАЧЕСТВЕННЫХ ОПУХОЛЕЙ У ЛИЦ МОЛОДОГО ВОЗРАСТА
}

\section{(C) Кузнецов Сергей Миронович}

кандидат медицинский наук, врач хирург высшей категории, заведующий операционным отделением, доцент кафедры факультетской хирургии s.m.kusnetzov@yandex.ru

\section{(C) Косолапов Юрий Леонидович}

подполковник медицинской службы, старший ординатор, хирург высшей категории y.kosolapov@mail.ru

\section{(C) Дармаев Андрей Дашиевич}

врач невролог высшей категории darmaevad@mail.ru

\section{(C) Гордеенок Федор Демидович}

ординатор хирургического отделения, заслуженный врач России, врач высшей категории s.m.kusnetzov@yandex.ru

\section{(С) Логинов Олег Станиславович}

хирург поликлинического отделения, врач высшей категории s.m.kusnetzov@yandex.ru

ФГКУ «425 ВГ» Минобороны России филиал № 1

Россия, 664009, г. Иркутск, ул. Госпитальная, 1

Аннотация. Злокачественные соединительно-тканные опухоли у молодых лиц встречаются редко, около $1 \%$ всех онкологических заболеваний. При этом их клиническая картина не имеет типичного проявления, что приводит к значительным диагностическим ошибкам, процент которых достигает до 60-90\%. Только тщательное клиническое обследование с применением современной аппаратуры дает возможность верифицировать патоло- 
гию. Мы приводим 4 клинических наблюдения, когда при первичной диагностике, врачи не предполагали наличие опухолевого процесса у молодых лиц.

Ключевые слова: соединительно-тканные опухоли, трудности диагностики, молодые лица.

\section{Для цитирования}

Онкологические казусы при диагностике соединительно-тканных злокачественных новообразований у лиц молодого возраста / С. М. Кузнецов [и др.] // Вестник Бурятского государственного университета. Медицина и формация. 2020. Вып. 1. С. 9-20.

\section{Введение}

Соединительно-тканные злокачественные опухоли мягких тканей являются относительно редким заболеванием, частота опухолей данной локализации составляет около $1 \%$ от всех злокачественных новообразований взрослых $[7,11]$. они с одинаковой частотой поражают лиц обоего пола, чаще в возрасте 20-30 лет. Около $1 / 3$ больных составляют лица моложе 30 лет. По данным некоторых авторов соединительно-тканные опухоли чаще локализуется в конечностях - $59 \%$ случаев, реже на туловище $19 \%$, забрюшинно - $15 \%$, в области головы и шеи - $9 \%$ случаев [9]. Соединительно-тканные опухоли по особенностям роста, клиническому течению и прогнозу относятся к числу наиболее злокачественных опухолей человека [3-5; 8]. Метастазирование в 70-80\% случаев происходит гематогенным путем [1;2; 4]. Трудности диагностики обусловлены большим числом нозологических форм и их вариантов, а как следствие сложностями их дифференциации, вариабельностью клинического течения и прогноза $[29 ; 11]$. Ошибки в распознавании СМТ на этапах амбулаторного обследования достигают 60-90\% [5]. Все это нередко приводит к частым врачебным ошибкам в вопросах диагностики и лечения, как на ранних, так и на поздних стадиях заболевания, необходимости выполнения обширных калечащих операций и неблагоприятным прогнозам заболевания $[2 ; 6]$.

Клиническое наблюдение № 1: Пациент Б. 28 лет поступил в хирургическое отделение 08.09.2018 г. с жалобами на наличие опухолевидного образования в правой паховой области. Из анамнеза болезни выяснено, полмесяца назад отметил у себя появление опухолевидного образования в правой паховой области. При прохождении очередного медицинского обследования хирургом верифицирована паховая грыжа, и пациент был направлен на плановое оперативное лечение в гарнизонный госпиталь: согласно медицинской документации, 03.10.2018 г. при прохождении УМО стационарно, хирургом выявлено наличие опухолевидного подкож- 
С. М. Кузнецов, Ю. С. Косолапов, А. Д. Дармаев и др. Онкологические казусы при диагностике соединительно-тканных злокачественных опухолей у лиц молодого возраста

ного образования в правой паховой области, выставлен предварительный диагноз: правосторонняя паховая грыжа. Рекомендовано стационарное обследование и лечение в условиях хирургического отделения. 08.11.2018 г. установленным порядком госпитализирован в хирургическое отделение филиала № 1 ФГКУ «425 ВГ» Минобороны России. При клиническом обследовании наличие грыжи исключено, по результатам УЗИ 12.11. 2018 г. выявлено очаговое образование мягких тканей правой подвздошной области, семенного канатика? возможно липома, лимфатические узлы? При ультразвуковом исследовании паховой области справа от 12.112018 г. Очаговое образование мягких тканей правой подвздошной области, семенного канатика? Возможно липома, лимфатические узлы?

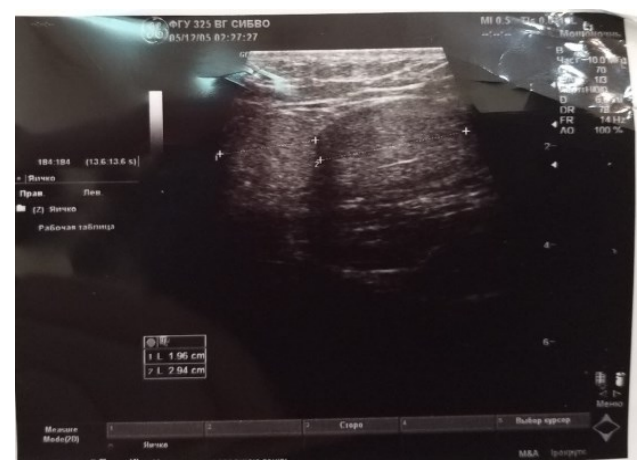

18.11.2018 г. пациенту выполнена операция удаление опухолевидного образования правой паховой области. В клетчатке по ходу семенного канатика обнаружено два связанных ножкой новообразования бобовидной формы, общим размером 6х8 см. Ножка инкапсулированного новообразования отходила от клетчатки пахового канала. Рана ушита, асептическая повязка. На разрезе опухоль сероватого цвета имеет слоистое строение. Макропрепарат с учетом макроскопического строения направлен для морфологического исследования в лабораторию ИООД. Где при комиссионном исследовании с участием специалистов Иркутска и СанктПетербурга верифицирована: Атипичная липоматозная опухоль (саркома).

Послеоперационный период гладкий, заживление раны первичным натяжением, швы удалены на 7-е сутки. Выписан под наблюдение медицинской службой части. Послеоперационный материал исследован в Иркутском областном онкологическом диспансере (ИООД) от 04.12.2018 г. № 2502-5/18: структура атипичной липоматозной опухоли (микропрепарат консультирован профессором Байковым В. В. г. Санкт-Петербург). Пациент взят под наблюдение онколога в ГБУЗ ИООД. По данному клиническому случаю выполнен запрос № 9146 в ФГКУ «ГВКГ им. Н. Н. Бурденко» 
Минобороны России. Получен ответ № 1871 от 24.12.2018 г. - учитывая результаты гистологического исследования и стадию заболевания, в проведении какого-либо противоопухолевого лечения не нуждается. По результатам гистологического исследования 18.12.2018 г. в ГБУЗ ИООД выполнена операция: широкое иссечение опухоли мягких тканей правой паховой области, орхофуникулэктомия справа, пластика раны местными тканями. Гистологическое исследование послеоперационного материала от 25.12.2018 г. № 20082/18 (12 кусочков): Лоскут кожи правой паховой области 7,5х2 см с подлежащей клетчаткой толщиной $7 \mathrm{~cm}$. На коже линейный рубец 5 см, в крае клетчатки яичко во влагалищной оболочке $6 \times 3,5 \times 3$ см с семенным канатиком 6 см. На разрезе в клетчатке под рубцом уплотнение звездчатой формы $4 \mathrm{x} 1,5$ см с тусклым желтым крапом. При микроскопии: в клетчатке рубцовые разрастания, продуктивное воспаление с пролиферацией липобластов. Яичко и придаток $(3,5 \mathrm{x} 1,9 \mathrm{~cm})$ обычного вида и строения. Выставлен диагноз: Саркома мягких тканей правой паховой области T16N0M0G1, 1а стадия, 3 клиническая группа. Послеоперационный период без особенностей, проведена антибактериальная и симптоматическая терапия, в удовлетворительном состоянии выписан под наблюдение хирурга по месту жительства. Рекомендовано контрольное обследование через 2 месяца). При контрольном обследовании по данным: УЗИ ОБИ, почек, забрюшинных и паховых лимфоузлов от 18.02.2019 г. выявлен в левой паховой области лимфоузел размерами 28x11 мм, с практически равной дифференцировкой слоев слабо неоднородной структуры; МСК ОГК 22.02.2019 г: единичные очаговые уплотнения в правом легком без динамики, больше данных за очаговый фиброз; уменьшение бронхопульмонального лимфоузла справа в динамике; УЗИ паховых лимфоузлов 22.03.2019 г: справа л/у не лоцируются; слева сохраняется л/у с равным соотношением слоев $25 \mathrm{x} 9$ мм, с неровным четким контуром (ранее $28 \times 11$ мм), рядом л/у обычного строения 12х6 мм.

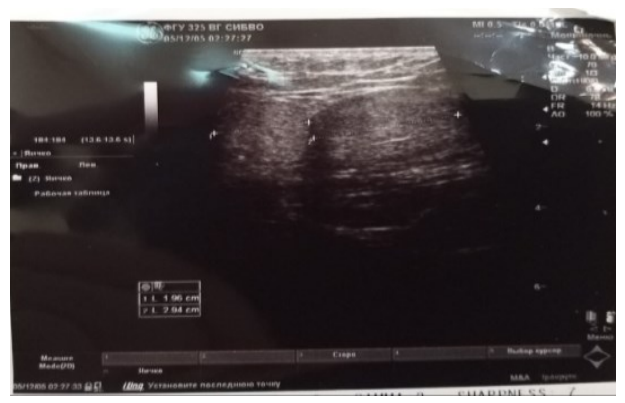


С. М. Кузнеиов, Ю. С. Косолапов, А. Д. Дармаев и др. Онкологические казусы при диагностике соединительно-тканных злокачественных опухолей у лиц молодого возраста

18.11.2018 г. пациенту выполнена операция удаление опухолевидного образования правой паховой области. В клетчатке по ходу семенного канатика обнаружено два связанных ножкой новообразования бобовидной формы, общим размером 6х8 см. Ножка инкапсулированного новообразования отходила от клетчатки пахового канала. Рана ушита, асептическая повязка. На разрезе опухоль сероватого цвета имеет слоистое строение. Макропрепарат с учетом макроскопического строения направлен для морфологического исследования в лабораторию ИООД. Где при комиссионном исследовании с участием специалистов Иркутска и СанктПетербурга верифицирована: Атипичная липоматозная опухоль (саркома). В последующем пациенту в ИООД 18.122019 г. была выполнена радикальная операция: Широкое иссечение м/тканей правой паховой области, орхидфуникулоэктомия справа, пластика местными тканями. При морфологическом исследовании метастазов по краям удаленных тканей не обнаружено. В последующем до заживления раны и по настоящее время находится под наблюдением хирурга гарнизонного госпиталя. Состояние удовлетворительное, данных за рецидив опухоли нет. Заключительный диагноз: Саркома мягких тканей правой паховой области T16N0M0G1, первая «а» стадия, третья клиническая группа. Широкое иссечение опухоли мягких тканей правой паховой области, орхофуникулэктомия справа, пластика раны местными тканями. Ангиодистония церебральных сосудов с элементами венозной дистонии, астеновегетативный синдром. Ожирение первой степени, алиментарно-конституционального генеза, стабильная стадия.

Клиническое наблюдение № 2: Пациент Б. 20 лет поступил в хирургическое отделение 12.03.2019 года с жалобами на наличие в левой паховой области плотного болезненного образования. При физической нагрузке и ходьбе отмечает усиление боли. Болен в течение 6 месяцев, когда отметил появление болезненного плотного образования в паховой области слева. После призыва в армию при физических нагрузках стал отмечать нарастающий болевой синдром врачом части направлен в гарнизонный госпиталь госпитализирован в хирургическое отделение. Ранее кроме простудных заболеваний, другим заболеваниями не страдал. Наследственность не отягощена. Вредные привычки отрицает, аллергических реакций не было.

Объективно: рост 180 см, окружность груди 79 см, вес при поступлении 53 кг. Состояние удовлетворительное. Астенического телосложения. Недостаточного питания (ИМТ 16,36). Цвет кожи и слизистых обычной окраски и влажности, теплые, тургор кожи сохранен. Подкожно-жировой слой не увеличен. Периферические лимфатические узлы не увеличены, не пальпируются, безболезненны. Щитовидная железа не пальпируется. Мышечная система развита удовлетворительно. Костно-суставная систе- 
ма развита нормально. Форма грудной клетки нормальная, не деформирована. Пальпация - безболезненна. Перкуторный звук легочный. Дыхание в легких везикулярное, хрипов нет. ЧДД 16 в минуту. Тоны сердца: ясные, ритмичные, ЧСС 86 в минуту. Пульс на лучевых артериях: удовлетворительного наполнения и напряжения. Частота пульса 86уд.в мин. Артериальное давление 115/75 мм рт. ст. Наружные половые органы не изменены. Мочеиспускание не затруднено, безболезненно. Язык при осмотре влажный, обложен белым налетом. Живот обычной формы и величины, не вздут, симметричный, участвует в акте дыхания; при пальпации мягкий, болезненный. Печень из-под края реберной дуги не выходит. Перкуторные границы не увеличены. Селезенка не пальпируется. Поколачивание по поясничной области безболезненное. Симптомы раздражения брюшины отрицательные. Аускультативно перистальтика прослушивается во всех отделах. Наружные половые органы не изменены. Мочеиспускание не затруднено, безболезненно.

Местно: в левой паховой области имеется плотное округлой формы образование в диаметре $2,5 \times 3,0$ cм, при пальпации плотное, резко болезненное. Паховое кольцо слева не расширено, симптом кашлевого толчка отрицательный.

Результаты клинических и биохимических анализов в пределах возрастной нормы, ЭКГ, ФЛГ без особенностей.

УЗИ паховых областей слева 13.03.2019 г. № 868: на УЗИ лоцируется смешанной эхогенности с жидкостным включением образование 5,8x4,7 см. Кровоток в образовании не определяется.

Рентгенография костей таза в прямой проекции 13.03.2019 г. № 703: на рентгенограмме костей таза определяется - больной плохо подготовлен, на этом фоне имеется смещение передней, верхней оси лобковой кости справа книзу, структурность дезорганизована с наличием зон склероза и эндостальной реакции. Рекомендовано МСКТ костей таза.

14.03.2019 г. № 12423: Проведено высокоразрешающее МСКТ исследование таза с первичной коллимацией $64 \times 0,6$ мм, толщиной реформатированных срезов 1,0-5,0 мм, с последующим трехмерным анализом изображений в MPRuVRT реконструкциях до и после внутривенного усиления. Аллергической реакции на введение контрастного препарата (Омнипак $350-50,0)$ не отмечено. Кости таза ассиметричны. Левая лонная кость деформирована, с выраженными зонами деструкции за счет наличия патологического образования неправильной формы, с четкими неровными контурами, размерами до $73 \times 52 \times 60$ мм, структура образования гетерогенная, ячеистая, представлена жидкостным (28-28 Ед.X и после контрастного усиления) и солидным компонентом (54 до и 79 Ед.Х после контрастного усиления). Образование в вентральных отделах про- 
С. М. Кузнеиов, Ю. С. Косолапов, А. Д. Дармаев и др. Онкологические казусы при диагностике соединительно-тканных злокачественных опухолей у лиц молодого возраста

лабирует в гребешковую и наружную запирательную мышцы слева, на фоне чего мышцы утолщены, оттеснены кпереди, в дорзальных отделах распространяется в полость малого таза, прорастая внутреннюю запирательную мышцу слева и оттесняя вправо и кверху мочевой пузырь. Предстательная железа с крупноволнистыми контурами, размерами до 41х39х25 мм (вертикальный-фронтальный-сагиттальный), с единичными мелкими кальцинатами в структуре. Перипростатическая клетчатка с тяжистыми включениями, местами облитерирована. Ректопростатическое пространство прослеживается фрагментами. Семенные пузырьки с волнистыми контурами, размерами 30х17 мм справа и 26х14 мм слева, достаточно однородной структуры. Мочевой пузырь умеренного наполнения, размерами 99х76 мм в сагиттальной плоскости, стенки пузыря толщиной до 2-3 мм, содержимое достаточно однородное. Кишечник подготовлен частично, стенки нормальной толщины. Увеличенных лимфоузлов в зоне сканирования не выявлено. УЗИ паховых областей слева 13.03.2019 г. № 868: на УЗИ лоцируется смешанной эхогенности с жидкостным включением образование $5,8 \times 4,7$ см. Кровоток в образовании не определяется. Рентгенография костей таза в прямой проекции 13.03.2019 г. № 703: на рентгенограмме костей таза определяется - больной плохо подготовлен, на этом фоне имеется смещение передней, верхней оси лобковой кости справа книзу, структурность дезорганизована с наличием зон склероза и эндостальной реакции.

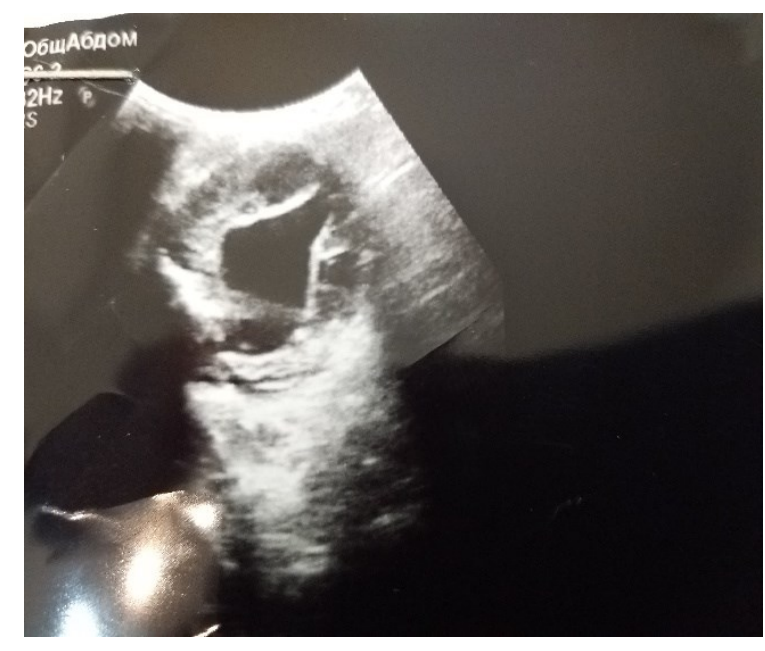

УЗИ паховой области от 13.03.2019 г.

От 13.03.2019 г. объемное образование левой паховой области. Объемное образование левой паховой области 


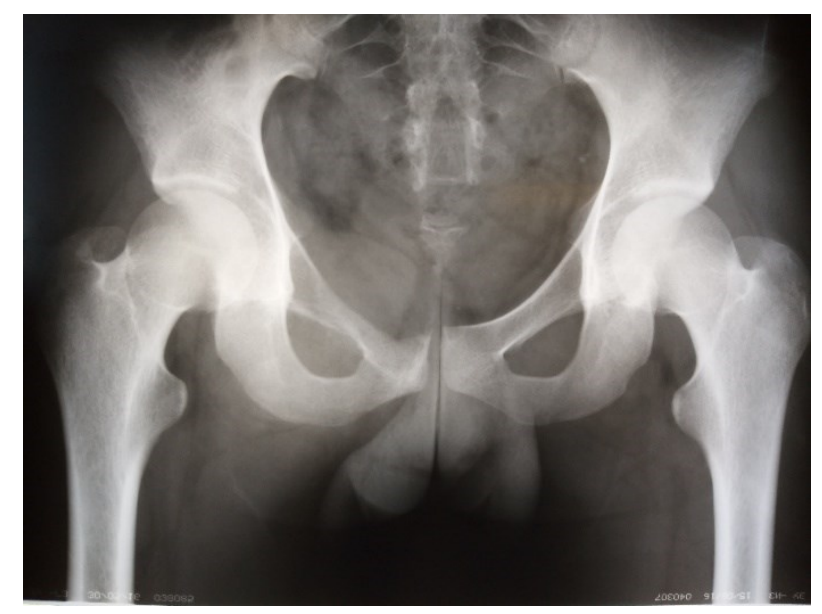

Рентгенография костей таза от 13.03.2019 г.

На основании обследования пациента верифицирована опухолевидное кистозно-солидное образование левой лонной кости, кальцинаты предстательной железы. злокачественная опухоль лонной кости слева. Пациент в установленном порядке переведен в специализированное отделение ЦВКГ им. Н. Н. Бурденко. Где пациент радикально оперирован прошел 6 курсов химиотерапии, выписан под наблюдение онколога по месту жительства.

Клиническое наблюдение № 3: Пациент Н. 21 года поступил в хирургическое отделение 29.10.2019 г. с жалобами на увеличение левого яичка, боли ноющего характера. Из анамнеза болезни выяснено, болен с 08.10. 2019 г. лечился в лазарете. Получал противовоспалительную терапию без эффекта. С 18.10. 2019 г. по 28.10.2019 г. находился на лечении в хирургическом отделении ГБУЗ «Аларская районная больница» с диагнозом: Острый левосторонний орхоэпидимит. Прошел курс противовоспалительной терапии, антибиотики, суспензорий, антибиотики, симптоматическую терапию. В связи с отсутствием положительной динамики переведен в хирургическое отделение гарнизонного госпиталя.

Объективно: состояние удовлетворительное, сознание ясное, правильного телосложения, повышенного питания. Рост $173 \mathrm{~cm}$, масса тела 75 кг окружность грудной клетки 102 см (ИМТ 25,06). Кожа и видимые слизистые обычной окраски. Подкожно-жировой слой, мышечная система и костно-суставная развиты хорошо и правильно. Периферические лимфоузлы не увеличены. Мышечная система развита хорошо. Костносуставная система без патологий. Грудная клетка правильной формы, перкуторно над всеми полями легочной звук, дыхание везикулярное, хрипов нет. Тоны сердца ясные, ритмичные. Пульс 84 уд. в мин., удовлетво- 
С. М. Кузнеиов, Ю. С. Косолапов, А. Д. Дармаев и др. Онкологические казусы при диагностике соединительно-тканных злокачественных опухолей у лиц молодого возраста

рительного качества. Артериальное давление 110 / 70 мм рт. ст. Живот не увеличен, при пальпации мягкий, безболезненный. Печень не пальпируется, селезенка не увеличена. Поколачивание по поясничной области безболезненное. Физиологические отправления в норме.

Местно: левое яичко до 4,0 см в диаметре, плотно-эластичной консистенции. В нижнем полисе определяется дополнительное повышенной плотности образование до $3,0 \mathrm{~cm}$.

При обследовании данные клинических и биохимических анализов в пределах физиологической нормы, ЭКГ, ФЛГ без патологии. УЗИ ОБП и почек 01.11.2019 г. № 2305: печень в размерах не увеличена, контуры ровные, структура однородная, эхогенность нормальная, очаговых изменений не выявлено, желчные протоки не расширены, v. portae в норме, холедох 0,3 см. Желчный пузырь 5,7x1,9 см, форма перегиб в теле, стенка не изменена, просвет пузыря гомогенный. Поджелудочная железа не увеличена, головка $1,7 \mathrm{~cm}$, тело $1,1 \mathrm{~cm}$, хвост 2 см, контуры ровные, эхогенность нормальная, структура однородная. Селезёнка в норме, структура однородная, эхогенность нормальная. Почки расположены (от купола диафрагмы, стоя (N до 5 см). Размеры: правая 9,7х3,8 см, паренхима 1,5 см, левая 9,5х4,7 см, паренхима 1,6 см, контуры ровные, ЧЛК недилатирован, однороден, паранефральная клетчатка без видимых изменений, дифференцировка на слои сохранена. Дополнительно: в левой половине брюшной полости, ниже хвоста поджелудочной железы определяется не правильной формы, неоднородное, средней эхогенности, без кровотока образование $11,9 \times 7,2 \times 5,6$ см. УЗИ мошонки 01.11.2019 г. № 2305: Правое яичко $3,9 \times 2,2 \mathrm{~cm}$, левое яичко $4,5 \times 2,9$ см, контуры ровные, структура однородная, очаговых изменений не выявлено. Придатки: справа головка $0,9 \times 0,8$ см, с ед. мелкими кистами. Слева головка: $1,6 \times 1,0$ см. Вены гроздевидного сплетения: не расширены. Объем свободной жидкости в оболочках яичек в пределах нормы. Дополнительно: В левом яичке неоднородное пониженной эхогенности, с жидкостным компонентом, с гиперэхогенными включениями образование 2,9х2,7 см. Выставлен диагноз: объемное образование левого яичка (семинома), объемное образование брюшной полости в области хвоста поджелудочной железы. Пациент в соответствии со стандартом оказания медицинской помощи направлен в профильное отделение ФГКУ «ГВКГ им Н. Н. Бурденко» Минобороны России.

Клиническое наблюдение № 4: Пациент Х. 19 лет поступил в гарнизонный госпиталь 08.09. 2019 г. с направительным диагнозом: Перелом левой ключицы. Предъявлял жалобы на болезненное образование в области левой ключицы; боли в области образования при движениях левой рукой. Со слов пациента, 07.09.2019 г. около 19:00, упал на левое плечо, ощутил боль в области левой ключицы, за медицинской помощью не об- 
ращался. Сохранялся болевой синдром в области левой ключицы, 08.09.2019 г. направлен на консультацию к хирургу филиала № 1 ФГКУ «425 ВГ» Минобороны России.

Рост 179 см, вес 64 кг окружность грудной клетки 91 см. Нормального питания (ИМТ 19,97). Общее состояние удовлетворительное. Сознание ясное. Кожа и видимые слизистые чистые, обычной влажности. Периферические лимфатические узлы не увеличены. Мышечная система развита хорошо. Грудная клетка правильной формы, перкуторно над всеми полями легочной звук, дыхание везикулярное, хрипов нет. Тоны сердца ясные, ритмичные. Пульс 60 уд. в мин., удовлетворительного качества. Артериальное давление 115 / 70 мм рт. ст. Живот не увеличен, при пальпации мягкий, безболезненный. Печень из-под края реберной не пальпируется, селезенка не увеличена. Поколачивание по поясничной области болезненное справа. Физиологические отправления в норме.

Местно: отека мягких тканей в области левой ключицы и левой руки нет. Периферическое кровоснабжение и иннервация левой руки не нарушены. Движения в левой руке в полном объеме. При пальпации в грудинном конце левой ключицы определяется разрастание кости в виде утолщения протяженностью до 5,0 см, при пальпации отмечается болезненность в области разрастания.

При дополнительном обследовании выявлено: результаты клинических и биохимических анализов в пределах возрастной нормы, ЭКГ, ФЛГ без особенностей. Рентгенография левой ключицы 09.09.2019 г. в грудинном конце левой ключицы определяется вздутие кости с истончением кортикального слоя и наличием множественных разнокалиберных участков просветления с тонкими стенками размерами 4,6х2,3 см. На этом фоне участков деструкции не выявлено.

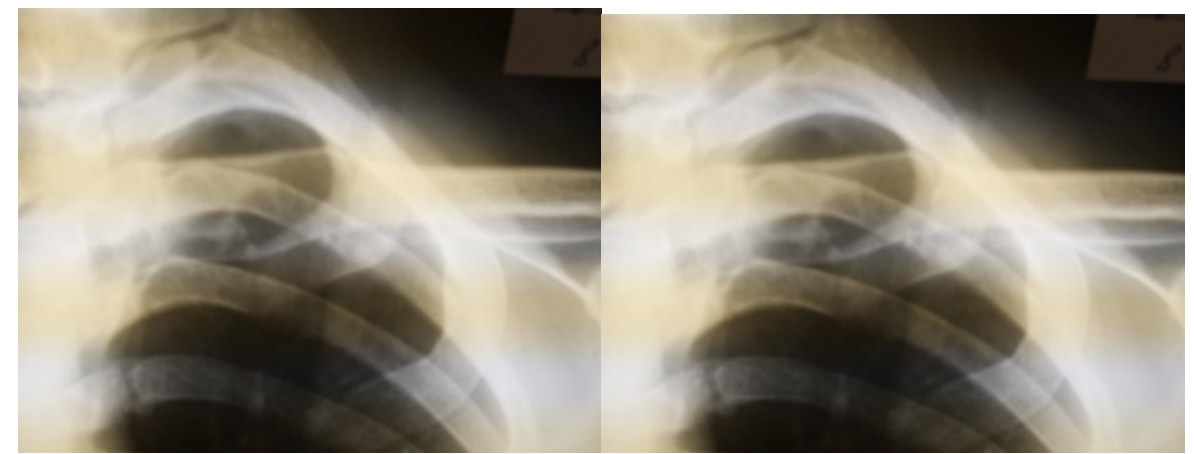

С клиническим диагнозом новообразование (остеобластокластома?) грудного конца левой ключицы направлен в специализированное отделение ФГКУ «ГВКГ им. Н. Н. Бурденко» Минобороны России. 
С. М. Кузнеиов, Ю. С. Косолапов, А. Д. Дармаев и др. Онкологические казусы при диагностике соединительно-тканных злокачественных опухолей у лиц молодого возраста

Выводы: 1. В приведенных наблюдениях ни в одном случае не было первичной верификации опухолевого поражения, хотя в последующем при простом клиническом обследовании было выявлено значительное расхождение в диагнозе.

2. В ранней диагностике злокачественных соединительно-тканных опухолей важное значение играет своевременное использование высоко разрещающих технологий.

3. Лечение пациентов должно проводиться в профильных лечебных учреждениях.

\section{Литература}

1. Абдуллаев Р. Я., Головко Т. С., Хвистюк А. Н. Ультразвуковая диагностика опухолей опорно-двигательного аппарата. Харьков: Новое слово, 2008. С. 128.

2. Алиев М. Д., Мехтиева Н. И., Бохян Б. Ю. Факторы прогноза сарком мягких тканей // Вопросы онкологии. 2005. Т. 51, № 3. С. 288-299.

3. Бебякин, В. Г., Минулин Ф. Ш. Ошибки в диагностике злокачественных опухолей мягких тканей // Вопросы онкологической помощи на этапе реформирования здравоохранения. Екатеринбург, 1996. С. 20-21

4. Ошибки диагностики сарком мягких тканей / Д. А. Буров [и др.] // Саркомы костей, мягких тканей и опухоли кожи. 2009. № 1. С. 48-53.

5. Веснин А. Г., Семёнов И. И. Атлас лучевой диагностики опухолей опорно-двигательного аппарата. Ч. 2. Опухоли мягких тканей. СПб.: Невский диалект, 2003. С. 182.

6. Веснин А. Г., Семенов И. И., Зайцев А. Н. Роль лучевых методов в диагностике сарком мягких тканей на амбулаторном этапе // Вопросы онкологии. 2000. Т. 46, № 3. С. 337-340.

7. Давыдов М. И., Аксель Е. М. Статистика злокачественных новообразований в России и странах СНГ в 2012 году // Вестник РОНЦ. М., 2014. C. 51-77.

8. Кочнева В. А. Клиника, дифференциальная диагностика и стадирование сарком мягких тканей // Практическая онкология. 2004. Т. 5, № 4. C. $237-242$.

9. Костякова Л. А., Синюков П. А. Возможности ультразвуковой томографии и допплерографии в диагностике новообразований мягких тканей конечностей и туловища // Тез. докл. 4 съезда Российской ассоциации специалистов УЗД в медицине. М., 2003. С. 272.

10. Редкий случай диагностики гигантской неврилеммоммы желудка / С. М. Кузнецов [и др.] // Актуальные опросы онкологии: сб. тр. Иркутск, 2002. C. 66. 
11. Ошибки в диагностике и лечение сарком мягких тканей / В. В. Тепляков [и др.] // Саркомы костей, мягких тканей и опухоли кожи. 2012. № 1. С. $29-35$.

\section{ONCOLOGICAL CASES IN DIAGNOSICS}

CONNECTIVE-TISSUE TUMORS IN YOUNG PEOPLE

Kuznetsov S. Mironovich

Doctor of Higher Category, Head of Operational Department,

Sociate Professor,

s.m.kusnetzov@yandex.ru

Kosolapov Yu. Leonidovich

Lieutenant Colonel of Medical Service,

Senior Intern, Surgeon of the Highest Category

y.kosolapov@mail.ru

Darmayev A. Dashievich

Doctor Neurologist of the Highest Category

Darmaevad@Mail.Ru

Gordeenok F. Demidovich

Resident at the Surgical Department

Honorary Doctor of Russia, Doctor of Higher Category

elenabotoeva@list.ru

Loginov O. Stanislavovich

Surgeon Polyclinic Department

Doctor of Higher Category

elenabotoeva@list.ru

Branch 1 Fgku «425-Vg» Mo RF

1, Hospital Str., Irkutsk, 664009, Russia

Abstract. Malignant connective tissue tumors in young people rarely occurs about $1 \%$ of all oncological diseases while thlier clinical picture das not have a typical manifestation which leads to significant diagnostic errosof $60 \%$ to $90 \%$ / We perent 4 clinical abservacions and when during the inicial diagnosis the doctors did not assume the presence of tumor processes in young people.

Keywords: connective- tissue- tumors diagnostic difficulties young faces. 